\title{
Formal and informal care for people with dementia: variations in costs over time
}

\author{
JUSTINE SCHNEIDER*, ANGELA HALLAM†, \\ M. KAMRUL ISLAM**, JOANNA MURRAY $\uparrow \dagger$, BETH FOLEY $\uparrow \dagger$, \\ LOUISE ATKINS $\uparrow \uparrow$, SUBE BANERJEE $\uparrow \dagger$ and ANTHONY MANN $\dagger \dagger$
}

\begin{abstract}
The services used by people with dementia and their carers were measured at three time points over I 7 months. This analysis is unusual in that both informal care and formal inputs were costed. The costs estimates for informal inputs developed here may be applied to other data sets. Two hypotheses to explain the inter-relationship between informal and formal care inputs, substitution and supplementation, were compared in analysing the data. This paper explores the variations in costs according to the living arrangements of the people with dementia, by level of dependency and over time, and finds systematic differences. The costs of the inputs from co-resident carers consistently exceeded the costs of formal services, with informal care constituting up to 40 per cent of the total costs burden for dementia care. When informal inputs were included, non-domestic residential care emerged as less, not more, costly than care in the community. There was a shift in costs burden from health services to social services over time as more people moved into non-domestic settings. Multivariate analyses identified several predictors of informal and formal care costs: physical disability, level of cognitive impairment, living in non-domestic settings, and formal care provided. Non-domestic care predicted lower inputs of both formal and informal services. Dementia level was positively associated with informal inputs. Physical frailty was associated with more formal care, but less informal care. More formal service inputs predicted higher informal care inputs. There is evidence of supplementation of informal care by formal services in the early stages of care, followed by substitution as the person with dementia enters residential care.
\end{abstract}

KEY WORDS - carers, dementia, community care, informal care, costs, substitution, supplementation.

* Centre for Applied Social Studies, University of Durham.

$\dagger$ Centre for the Economics of Mental Health, Institute of Psychiatry, King's College, London.

** Department of Economics, Jahangirnagar University, Bangladesh.

$\dagger \dagger$ Section of Epidemiology, Institute of Psychiatry, King's College, London. 


\section{Background}

There is wide recognition in the western world of the need to plan for the growing number of older people who will require health or social care. The expected growth in demand for care is attributed largely to people surviving longer. In addition, the principles of 'community care' - enabling people to remain in their own homes for as long as possible or as long as they wish to do so-present complex challenges for planners, providers and carers. These challenges include questions about the ethics, the effectiveness and the costs of supporting elderly people who need care. Added to these challenges are policy-related questions about the respective responsibility of individuals, families and the state in providing care, or in paying for it.

Considerable intellectual power has already been brought to bear on these issues. In the United Kingdom, these include a Royal Commission on Long Term Care for the Elderly (Department of Health 1999) and the response to this report within the National Health Service Plan (Department of Health 2000). These two documents provide a useful anchor point for the data reported here. One of the Royal Commission's recommendations was that the government should ascertain precisely how much money is spent on supporting people in their own homes and in residential care. The government's response to this recommendation is that there is a need to 'get the right incentives in the system to promote older people's independence and to provide care closer to home', and that, in this regard, the promotion of 'intermediate care' is seen as a positive step (Department of Health 2000). Clearly, the calculation of precise costs for all support for older people would be a gargantuan task. However, without such information, it is impossible to estimate the cost effectiveness of intermediate care or any alternative provision.

The data presented here represent one attempt to measure all the costs of caring for a particular group of older people, those with dementia who have informal carers. In doing so, we are focusing on a particularly complex area within the arena of care for older people. Dementia is a progressive and terminal condition. Despite the recent introduction of anti-dementia medication, there remains little that can be done medically to ameliorate an individual patient's disease, although there are some clinical, social and behavioural interventions that may help at times. For carers looking after people with dementia, there is extensive evidence that the experience can be detrimental, both physically and psychologically (O'Rouke and Tuokko 2000). It may also have a negative financial impact. While a systematic review of the effectiveness of interventions for carers found few studies that could be subjected to meta-analysis (Thompson and Spilsbury I998), 
there is some evidence of interventions that benefit carers, such as counselling for the carers themselves (Mittelman et al. I993) and health or personal care for the person with dementia (Bass et al. I996). Day care and/or sitting have been shown to be associated with people with dementia remaining longer in their own homes (Levin et al. I994). This is presumably because of the relief given to carers. We need detailed information about who uses which formal services to deploy these most efficaciously. Likewise, in planning long-term care in the community, it is vital to understand and, if possible, to quantify the contribution of informal carers. Only then can we assess the effects that formal services might have in supporting individuals and their carers, and how much these services cost. This paper does not address questions of effectiveness, but rather prepares the ground further for studying interventions to support carers.

\section{Theoretical perspectives}

Lyons and Zarit (I999) review models that seek to explain the interaction between formal and informal support. These include substitution (Greene I983) and supplementation (Edelman and Perry i99o). The former states that most carers would opt for formal services to take over the caring function, if this were possible. The latter states that formal services are complementary to informal care provided, but in effect do not reduce the informal carer's role. A third explanation of the relationship between formal and informal care is specialisation; the provision of different types of care by formal and informal agents, meaning that each has specific domains of responsibility where the other does not normally operate. None of these accounts addresses the perspectives of the people concerned, their interpersonal relationships or networks of social support, which have been the focus of other theorists reviewed by Lyons and Zarit (i999: I85). We did not collect data in sufficient detail to test the specialisation hypothesis. For our purposes, the hypotheses of substitution and supplementation are a useful adjunct to the analysis of the data presented here. If substitution could be shown to prevail, then, for a given person with dementia, greater involvement by informal carers might be associated with a reduced involvement by health and social services, and vice versa. If, however, the supplementation hypothesis proved a better explanation of the relationship between formal and informal services, then as one increased the other would also do so. Service providers could then predict the likely impact of increasing or decreasing provision, other things being equal. 


\section{Method}

A longitudinal study of 132 people with dementia and their carers living in the community was carried out in south London in I997-I999. It set out to explore the impact of caring on carers over time, and to measure the service use and comprehensive costs of living in the community for each household. Time 2 was six to nine months after the first interview, and Time 3 was on average i7 months after the first interview. The sample of people with dementia was drawn from caseloads of community-based, psycho-geriatric services. All had a formal diagnosis of moderate to severe dementia, and were known to specialist services. We further selected people who were receiving support from a family member or friend who could be seen as the 'carer'. The criterion for being a carer was spending four hours or more per week with the individual with dementia. A proportion of these people were already living in residential or nursing homes but nevertheless had carers by our definition at the start of the study. The sample achieved was exhaustive of all the carer cared-for person dyads in the clinical caseloads available to us.

Carers were interviewed using, among other instruments, the 'Client Service Receipt Inventory' (Beecham and Knapp I992), which measures the services consumed, and details of housing sufficient to permit costing; and the 'Caregiver Activity Survey' (CAS) (Davis et al. I997), which asks carers to estimate the amount of time they spend on six specific activities in relation to the person cared for. The CAS has been found to have test-retest reliability over a three-week period, and to be sensitive to change in levels of dependency in a cohort of 20 people with Alzheimer's disease and their carers over an I8-month period (Marin et al. 2000). Carers whose relative died during the study were retained for the purpose of data collection but here we report the results for the carers whose cared-for person was still alive at each time point.

In relation to the person with dementia the following instruments were used: the 'Activities of Daily Living' (ADL) assessment (Katz et al. I963), which measures the limits on the activities of the person with dementia, the 'Clinical Dementia Rating Scale' (CDR) (Hughes et al. I982), and the 'Global Deterioration Scale' (GDS) (Reisberg et al. I982).

\section{Approach to data analysis}

The data were analysed according to the living arrangements of each person with dementia. This is not only because accommodation makes up a large proportion of most people's costs (Knapp and Beecham I995), but also because the configuration of services received by individuals in different 
living situations was found to differ systematically (Schneider et al. 2002). The categories used here refer to three types of living arrangements; alone, with a carer, and residential or nursing home ('non-domestic') care. ${ }^{\mathbf{1 , 2}}$

\section{Costing method}

We measured service use at three time points with the 'Client Service Receipt' Inventory (CSRI). The CSRI is a flexible schedule that has been used in many studies. The inventory collects data relating to the subject's (and carer's) accommodation arrangements, income and expenditure, the carer's present or most recent employment, and services used by the subject during the last three months. The service user's medication profile is also collected.

\section{Informal care costs}

The main objective of this study was an examination of the hypothetical cost of providing informal care. This is a complex area where no consensus on methodology exists. For a discussion of the different costs that could be applied to informal care, see Islam (I999). There are two principal health economics approaches to the valuation of carers' time: opportunity cost and market value. In the former, the best alternative use of the carer's time is taken to indicate the value of that time spent in caring. If a carer gives up paid work to care, the lost earnings are estimated. As I2 I of the I 32 carers in our study were not working, we assumed that the carers were devoting to caring tasks time that would not otherwise be waged, and costed this time following a market value approach.

The market value approach applies a wage rate for paid staff supplying the same service as the carer, such as a nurse, cleaner or companion. This can impute different wage rates for different activities, but it demands detailed information about the carer's activities. Our chosen instrument, the 'Caregiver Activity Survey' (Davis et al. I997) distinguishes among numerous activities, which have been grouped into three principal forms of caring tasks, or activities of daily living:

- general tasks, such as communicating with the person with dementia, paperwork, household chores, shopping, cooking and eating meals;

- specific tasks, personal care, or providing transport for the person with dementia, and

- supervision, during which time the carer might do something which was not directly part of the care function, such as reading, entertaining visitors or watching television. 
A few carers reported that they spent more hours than there are in one day in caring activities. Where the mean total number of hours caring was reported to exceed 24, the number of hours of supervision was adjusted downwards, on the assumption that active caring tasks took precedence over supervision. This affected three cases. For clarity, we have followed a simple and conservative approach to costing. This permits the results to be varied if other options are preferred. For non-co-resident carers the time used in general tasks could be seen as additional to that time spent meeting their own personal needs for these tasks, but for co-residents this difference was assumed to be negligible. Hence, general tasks were costed for carers who lived elsewhere, but not for co-residents. Specific tasks were costed for both groups. Supervision was costed separately, both because of the wide variation in supervision time and because of the question whether this should be costed or not. It could be assumed that if a person is not coresident they incur additional travel costs, but these have been omitted here - with the effect that our informal care costs are relatively conservative.

A single cost is used for each category of care tasks, with no variations according to whether the carer is or was employed elsewhere. For specific tasks we have taken the home care unit cost of $\mathcal{E}_{\mathrm{i}} \mathrm{o}$.30 per hour in 1999 (Netten et al. 1999). This is taken as the market value of replacing the labour of the carer when that person is engaged in semi-skilled caring tasks such as bathing and dressing. It does not necessarily reflect the wage of the home carer, because the cost comprises an element for agency overheads. For general tasks and supervision, which are arguably unskilled tasks, we have taken the I999-2000 national minimum wage of $£ 3.60$ as an estimate of minimum costs.

\section{Accommodation costs}

For our purposes, all elements of the costs of domestic housing for subjects and their carers were examined in detail, as well as the full costs of residential or nursing home care. For people being cared for in domestic housing, many formal cost items would be the same as those falling to a healthy householder (e.g. food, heat, lighting, water and rent). Such items would need to be included in any comparison with the costs of specialist care because they are the 'hotel' services provided as part of a package in residential and nursing homes.

In order to estimate the long-run marginal (opportunity) costs of premises occupied, the cost implications of these buildings must be included in the total cost. A market valuation was estimated for every property owned or rented by a service user taking part in the study and their principal carer (if living separately). Mean property prices in Greater London were taken 
(Halifax Building Society 1998) for each type of dwelling: flat/maisonette, terraced, semi-detached, detached house. Prices were deflated to represent the situation in $1997^{-98}$ and used as written for owner-occupied property. In order to estimate the true value of public housing, it was important to allow for the discount rate which would be offered to tenants if they were buying the property (Government Statistical Service I998). The percentage difference between the average prices of property mortgaged to local authority sitting tenants (including the estimated discount) and other first time purchasers during one year was calculated (DETR 1998) and this percentage removed to arrive at local authority property prices.

Where carers were employed, their occupations were classified by socioeconomic category. The classification allows an estimate to be made of income levels within households without asking direct questions at interview about rates of pay. Average gross weekly pay for each category was used to estimate household income (Office of National Statistics I999a). Average gross weekly earnings by major occupational groups as at April I 998 were used but, in order to reflect the same financial year as all other costs data, half the annual percentage increase was removed from these amounts. Once income levels had been calculated, it was possible to calculate average household expenditure. For this, the Family Expenditure Survey (FES) for I997-98 was used (Office of National Statistics I999 b).

Specific fee details for individual residential and nursing homes were used if available and, if not, national unit costs with appropriate adjustments for London were taken (Netten et al. 1998). Where people were living permanently in residential or nursing homes, it was assumed that any income they received would go towards meeting the fee, leaving them with a minimum personal allowance of $\mathcal{E}_{\mathrm{I}} 4$. Io per week. For sheltered housing arrangements, the rent amounts recorded in the CSRI might not represent the full costs of running the facility (for example if an unknown amount of housing benefit was being contributed as well as rent payments by the subject) so national unit cost calculations were used throughout.

\section{Other services}

Health and social care services used were estimated using national unit costs data (Netten et al. 1998). All hospital services, day services and the time of community-based professionals were costed in this way. Where appropriate, we were able to reflect higher salary costs due to London weighting, and travel costs for professionals making domiciliary visits. One day centre, which was used by a number of the study's subjects, was costed from facility accounts information. The medication profile for each subject was collected as part of the CSRI. ${ }^{3}$ 


\section{Costs analysis}

Several difficulties in analysing costs of care have been outlined by Gray et al. (I997), Drummond and Jefferson (i996) and Chisholm (2000). These arise from the fact that many people use few services, while a few people use a great many, resulting in skewed distributions with a high proportion of zero values. We address these problems in several ways. First, we include the mean, standard deviation, median and inter-quartile range for each variable. Where costs data are positively skewed, we carry out logarithmic transformations - this means that all costs are transformed before analysis except accommodation costs. Then, when comparing mean costs, we proceed cautiously. ${ }^{4}$

\section{Associations between formal and informal inputs}

The predictors of costs of informal and formal care were explored using multivariate analysis. Independent variables included informal care, disability and place of residence. In the discussion that follows of the findings, the merits of and insights from the rival theories of substitution and supplementation are considered.

\section{Findings}

\section{The sample}

The sample of 132 people with dementia and their I 32 carers has been described fully elsewhere (Schneider et al. 2002). Sixty four per cent of the people with dementia were female, and 72 per cent of the carers were female. Patients with co-resident carers were significantly younger than patients in the other two groups (ANOVA p < o.oor, df 2, F= II.3), while co-resident carers were significantly older than the other two groups of carers (ANOVA p $=0.00 \mathrm{I}, \mathrm{df} 2, \mathrm{~F}=7.7)$. This indicates that the co-resident carers were mostly of the same generation as the patients, while more crossgenerational caring occurred in the non-co-resident and non-domestic (residential) care groups. Indeed, the co-resident carers were predominantly spouses. Taking all three categories of living arrangements together, the most frequent relationship of the carer to the patient was son $(\mathrm{N}=\mathrm{I} 4)$ or daughter $(\mathrm{N}=4 \mathrm{I})$.

The 'Global Deterioration Scale' (GDS) for the whole sample was normally distributed, with a mean of 4.4 (standard deviation I.34, $\mathrm{N}=\mathrm{I} 23$ ). The levels of disability varied significantly between the three groups. ${ }^{\mathbf{5}}$ When the three groups were compared on a measure of physical dependency 
(Katz Activities of Daily Living score), differences were not significant between the three types of living arrangements. In view, therefore, of the findings of significant differences in GDS according to living arrangements, we tested some of the results presented below for the impact of level of disability as measured by the GDS. This was done by inspecting the distribution of GDS scores, selecting only those individuals whose GDS score was greater than 4 , and repeating the analyses of differences for this subsample, who were thus those people more severely affected by dementia. This can be seen as a test of the sensitivity of our results to level of dementia. Ninety-two of the original sample of I 32 people had a GDS score of $4+$ at Time I. Analysis of variance for the sub-sample selected here indicated that people living alone still had significantly lower GDS scores than those in non-domestic care, but neither of these two groups differed significantly from those with co-resident carers.

\section{Type of accommodation}

At the outset, I9 people were living in residential homes, I2 in nursing homes and I 3 people were in sheltered housing. Sheltered housing provides a minimal level of surveillance, often through the availability of a resident 'warden' who might, for example, check on residents daily and respond to emergency calls day and night. However, the accommodation is otherwise self-contained, and so for our purposes is treated here as community-based ('domestic') living. Residential and nursing homes were taken together as 'non-domestic' settings.

\section{Trajectories}

The living and care arrangements of the original sample at Time 2 and Time 3 are shown in Figure I. It illustrates that the proportion of the sample living in the community declined over the I7 months of the study, while the proportion of people in non-domestic care increased at Time 2, then dropped by Time 3, due to a high proportion of deaths (39\%).

\section{Informal care input}

Informal care input of four hours per week was a criterion for admission to this study. It is not surprising, therefore, that people in residential care received an average of just over four hours per week at Time I. By comparison, people with co-resident carers were getting 75 hours of informal care per week, and those living alone received 24 hours at the same stage in the study. The mean number of hours of informal care received by 
312 Justine Schneider, Angela Hallam, M. Kamrul Islam et al.

T A B L E I. Costs of informal care by living arrangements in 1999

\begin{tabular}{|c|c|c|c|c|c|c|}
\hline$£$ per week & Mean & Std Deviation & Median & Percentile 25 & Percentile 75 & Valid N \\
\hline \multicolumn{7}{|c|}{ Time I } \\
\hline Non-domestic & I8.85 & 35.67 & $4 \cdot 73$ & 0.00 & I 4.63 & $3 \mathrm{I}$ \\
\hline Co-resident & 249.07 & 284.63 & I 23.56 & I9.6o & 506.64 & 63 \\
\hline Alone & II 5.94 & I5 1.74 & 42.00 & $5 \cdot 5^{\mathrm{I}}$ & I94.I3 & 37 \\
\hline All & I56.99 & $233 \cdot 34$ & 42.57 & 4.20 & 203.83 & I $3 \mathrm{I}$ \\
\hline \multicolumn{7}{|c|}{ Time 3} \\
\hline Non-domestic & 31.62 & 64.00 & 0.00 & 0.00 & $5^{0.40}$ & 34 \\
\hline Co-resident & I 83.78 & I $94 \cdot 32$ & 75.25 & 24.03 & $35^{2} .5^{\mathrm{I}}$ & 33 \\
\hline Alone & 96.05 & I03.93 & $77 \cdot 3^{2}$ & 7.87 & 207.03 & 7 \\
\hline All & I05.00 & I 55.90 & 43.85 & 0.00 & I $25 \cdot 12$ & 75 \\
\hline \multicolumn{7}{|c|}{ More severely affected (GDS $4+$ ) at Time I } \\
\hline Non-domestic & $2 \mathrm{I} .5^{6}$ & $37 \cdot 53$ & 9. Io & 0.00 & $24 \cdot 33$ & 27 \\
\hline Co-resident & 310.8I & 296.79 & 201.34 & $37 \cdot 55$ & $599 \cdot 77$ & 47 \\
\hline Alone & I3O.II & I72.6I & 70.35 & II. 29 & 225.79 & I8 \\
\hline All & I90.57 & $259 \cdot 15$ & $5^{8.7 \mathrm{I}}$ & 6.12 & 297.07 & 92 \\
\hline
\end{tabular}

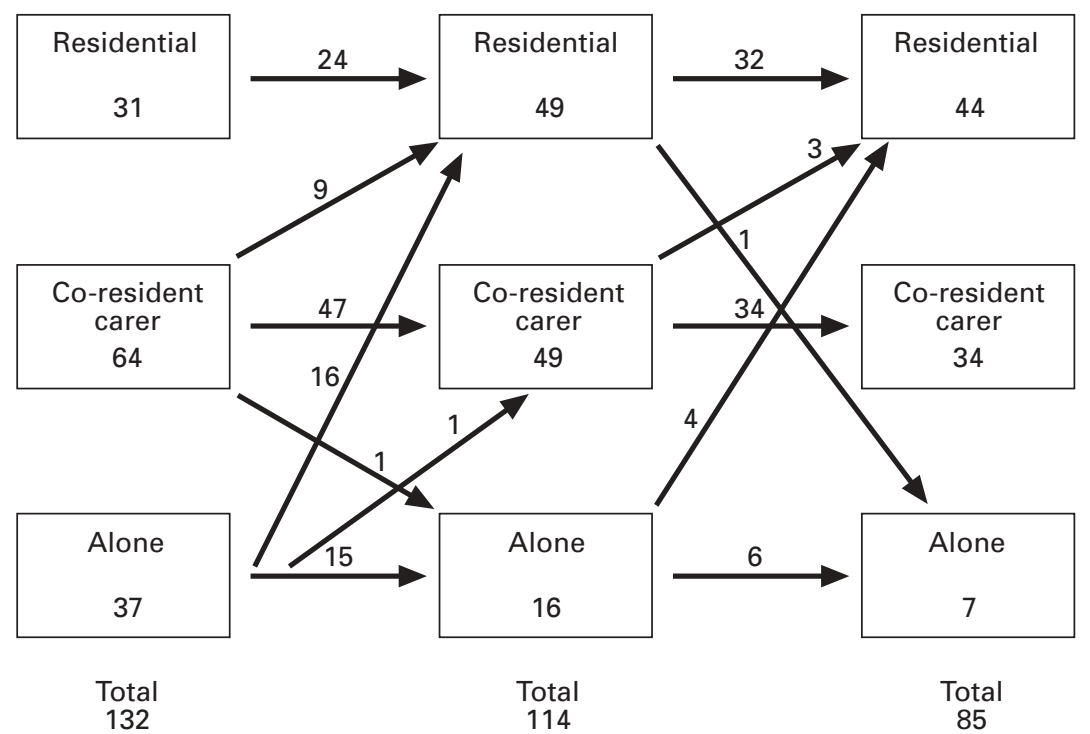

Figure I. Trajectories of numbers of study subjects.

the whole sample was 44 per week at Time I, and 34 per week at Time 3, when 39 per cent of the sample had died. Detail of the number of hours and type of informal care provided is given elsewhere (Schneider et al. 2002). Table I reports the results when costs, devised in the manner described above, are applied to informal care hours. It includes the costs of providing informal care for people with higher levels of GDS at Time I. 


\section{All costs}

The detailed distribution of all costs for the whole sample at three time points is too lengthy to present here but is available from the authors on request. As anticipated, most distributions are skewed, requiring statistical comparisons to be made cautiously. Tables $2-4$ compare people living in residential care with those living in the community at three time points. Because informal care costs were not measured at Time 2, 'total' costs which include this element, formal care and accommodation are not shown in Table 3. 'Community health care' includes contacts with community psychiatric nurses, psychologists and community psychiatrists. 'NHS total' represents the sum of inpatient, outpatient, day hospital, community health and primary care costs. In the following sections, the differences in costs between people in different types of living arrangements are explored. Changes in costs over the course of the study are then examined, considering the impact of disability on costs. Finally, we explore the predictors of formal and informal care inputs.

\section{Differences at Time I}

The strongest differences between people in non-domestic and community settings were found at Time I, when ten analyses show nine significant differences (Table 2). With the exception of accommodation, which was less costly, these differences all show higher costs of services for people living in the community. Consequent upon these differences, two aggregate variables also emerged as significantly higher for community-dwellers: all service costs (health and social care); and total costs (formal services, informal care and accommodation). Although non-domestic accommodation cost more, total costs of care were higher at Time i for people in domestic living arrangements, due to the higher level of formal and informal inputs.

Not surprisingly, as shown in Table 2, services that are designed to support people living in the community, did cost significantly more for such people than for those in non-domestic care at Time I. This was true for day centres, community health, social services (social work, home care and meals on wheels) and respite care. It is somewhat surprising that people in non-domestic settings should receive less outpatient care, although this may reflect the nursing element of the support provided in some care environments. This difference was only found at Time I and in view of the large number of analyses performed on these data may be spurious.

The finding that some people living in non-domestic care have used services normally destined for people living in the community (day care, respite care) may have two alternative but not mutually exclusive 
T A в L E 2. Weekly care costs: non-domestic and domestic-dwellers at Time I

\begin{tabular}{|c|c|c|c|c|c|c|}
\hline \multirow[b]{2}{*}{ Cost item } & \multicolumn{2}{|c|}{$\begin{array}{l}\text { Significance of } \\
\text { differences }\end{array}$} & \multicolumn{2}{|c|}{$\begin{array}{l}\text { Community dwelling } \\
\qquad(\mathrm{n}=\mathrm{IOI})\end{array}$} & \multicolumn{2}{|c|}{$\begin{array}{l}\text { Non-domestic care } \\
\qquad(\mathrm{n}=3 \mathrm{I})\end{array}$} \\
\hline & t-test ${ }^{1}$ & $M-W^{2}$ & Mean & Median & Mean & Median \\
\hline Accommodation (pwd) & 0.023 & $0.06 \mathrm{I}$ & I89.34 & 183.80 & 253.63 & $22 \mathrm{I} .20$ \\
\hline Outpatient & $<$ O.OOI & 0.008 & 3.75 & 0.00 & 0.57 & 0.00 \\
\hline Day centre & $<$ O.OOI & $<0.001$ & 82.03 & 0.00 & 7.04 & 0.00 \\
\hline Community health & $<$ O.OOI & $<0.001$ & 9.28 & 3.17 & I.I3 & 0.00 \\
\hline Social services & $<$ o.oOI & $<0.001$ & 105.72 & 37.68 & $7 \cdot 16$ & 0.00 \\
\hline Respite & $<$ o.oOI & 0.015 & $\mathrm{I} 3 \cdot 5^{2}$ & 0.00 & 0.00 & 0.00 \\
\hline NHS total & $<$ o.0OI & $<0.001$ & $4^{8.74}$ & $\mathrm{I} 4 \cdot 3^{2}$ & 24.88 & $2 \cdot 3^{8}$ \\
\hline All services & $<$ O.OOI & $<0.001$ & I54.94 & III.I9 & 32.04 & $3 \cdot 45$ \\
\hline Informal care & $<$ O.OOI & $<0.001$ & I99.8I & 89.86 & I8.85 & 4.73 \\
\hline Total costs & $<$ O.OOI & $<0.001$ & 54I.80 & $460.8 \mathrm{I}$ & $304 \cdot 5^{\mathrm{I}}$ & 269.II \\
\hline
\end{tabular}

Notes: pwd - person with dementia.

${ }^{1}$ All t-tests were performed on $\log _{10}$ of the costs $(\mathcal{E})$, except for accommodation costs, and total costs $\mathrm{T}_{\mathrm{I}}$, which were not transformed.

${ }^{2}$ Mann-Whitney non-parametric test was used as an alternative.

T А в L E 3. Weekly care costs: non-domestic and domestic-dwellers at Time 2

\begin{tabular}{|c|c|c|c|c|c|c|}
\hline \multirow[b]{2}{*}{ Cost item } & \multicolumn{2}{|c|}{$\begin{array}{l}\text { Significance of } \\
\text { differences }\end{array}$} & \multicolumn{2}{|c|}{$\begin{array}{l}\text { Community dwelling } \\
\qquad(\mathrm{n}=67)\end{array}$} & \multicolumn{2}{|c|}{$\begin{array}{l}\text { Non-domestic care } \\
\qquad(\mathrm{n}=49)\end{array}$} \\
\hline & t-test ${ }^{1}$ & M-W ${ }^{2}$ & Mean & Median & Mean & Median \\
\hline Accommodation (pwd) & $<0.001$ & $<0.001$ & I8I.28 & I66.80 & 375.59 & 352.10 \\
\hline Day centre & 0.035 & 0.037 & 6г.07 & 0.00 & $3^{\mathrm{I}} \cdot 3^{8}$ & 0.00 \\
\hline Community health & $<0.001$ & $<0.001$ & 9.27 & 2.67 & I.72 & 0.00 \\
\hline Social services & $<0.001$ & $<0.00 \mathrm{I}$ & 103.87 & 67.20 & I. 72 & 0.00 \\
\hline Respite & 0.013 & 0.023 & 9.93 & 0.00 & I. 94 & 0.00 \\
\hline NHS total & 0.044 & $0.01 \mathrm{I}$ & 59.53 & 17.14 & 60.28 & 5.65 \\
\hline All services & $<0.001$ & 0.001 & $\begin{array}{r}159.42 \\
152-1\end{array}$ & 105.70 & IOI.27 & II. 58 \\
\hline
\end{tabular}

Notes: pwd - person with dementia.

1 All t-tests were performed on $\log _{10}$ of the costs $(\mathcal{E})$, except for accommodation costs, which were not transformed.

${ }^{2}$ Mann-Whitney non-parametric test was used as an alternative.

explanations; either they used these services in the past three months and prior to admission, or they used them while in residential or nursing care (or both). For instance, some care homes also provide day care to local people, and their own residents may attend at the same time. Despite sample attrition, most of these differences between variables retained their statistical significance at Time 2 (Table 3), when only outpatient care ceased to be significant (informal care was not measured at Time 2). Again, most were still significant at Time 3 (Table 4 ). The overall picture is one of higher costs for people living in the community when informal care is taken into account. 
T А в L E 4. Weekly care costs: non-domestic and domestic-dwellers at Time 3

\begin{tabular}{|c|c|c|c|c|c|c|}
\hline \multirow[b]{2}{*}{ Cost item } & \multicolumn{2}{|c|}{$\begin{array}{l}\text { Significance of } \\
\text { differences }\end{array}$} & \multicolumn{2}{|c|}{$\begin{array}{l}\text { Community dwelling } \\
\qquad(\mathrm{n}=4 \mathrm{I})\end{array}$} & \multicolumn{2}{|c|}{$\begin{array}{l}\text { Non-domestic care } \\
\quad(\mathrm{n}=40)\end{array}$} \\
\hline & t-test ${ }^{1}$ & $\mathrm{M}-\mathrm{W}^{2}$ & Mean & Median & Mean & Median \\
\hline Accommodation (pwd) & $<$ o.oOI & $<$ o.oOI & I76.29 & I66.8o & 368.66 & $35^{2.10}$ \\
\hline Day centre & 0.008 & 0.010 & $55 \cdot 73$ & 0.00 & $\mathrm{I} 3.43$ & 0.00 \\
\hline Community health & 0.006 & о.оI6 & $10.5^{\mathrm{I}}$ & 2.19 & 2.90 & 0.00 \\
\hline Social services & $<$ o.oOI & $<0.00 \mathrm{I}$ & Iog. $5^{8}$ & 85.66 & 20.92 & 0.00 \\
\hline Respite & O.OII & 0.018 & $\mathrm{I} 6.5^{\mathrm{I}}$ & 0.00 & 2.98 & 0.00 \\
\hline All services & 0.003 & 0.003 & I66.59 & I5 1.70 & II 6.23 & $15 \cdot 47$ \\
\hline Informal care & $<$ O.OOI & $<0.00 \mathrm{I}$ & I65.85 & 72.98 & $3^{\text {I.62 }}$ & 0.00 \\
\hline Total costs & o. 659 & 0.746 & 52 I.IO & $495 \cdot 9^{8}$ & $49^{6.46}$ & $449 \cdot 53$ \\
\hline
\end{tabular}

Notes: pwd-person with dementia.

1 All t-tests were performed on $\log _{10}$ of the $\operatorname{costs}(£)$, except for accommodation costs, which were not transformed.

${ }^{2}$ Mann-Whitney non-parametric test was used as an alternative.

\section{Comparing people with co-resident carers}

We went on to explore differences in costs between people who lived in the community with co-resident carers and those who lived alone. Because of the low use of some services and the attrition in sample size over time, few of these differences proved statistically significant at Times 2 and 3 (Table 5). At Time I, however, there were clear differences. The cost of accommodation was higher for people living alone, but at Times 2 and 3 , the differences in accommodation for the person with dementia disappeared. People living alone had lower costs for medication, outpatient care, primary care and consequently for NHS services overall. They had slightly higher costs for community health care (for example, community psychiatric nursing) and this was marginally statistically significant (independent means $\mathrm{t}=\mathrm{I} .9, \mathrm{p}=0.05 \mathrm{I}$; Mann-Whitney $\mathrm{U}=85^{2}$, $\left.\mathrm{p}=0.0 \mathrm{I} 6\right)$. Principally due to the fall in numbers (only seven people living alone at Time 3), the levels of significance of the differences declined, and those that remained ceased to be confirmed by non-parametric tests. The greater use of NHS services by people with co-resident carers over people living alone was highly significant at Time I, but not at Times 2 or 3 . Because the differences noted cancel each other out, the overall use of formal services did not differ between the two groups at any time point.

\section{Tests of sensitivity}

Separate analyses for people with GDS scores of $4+$ reinforce the picture of higher costs for community-dwelling individuals (not shown). All of the differences in Table 4 were confirmed by tests of significance on the 
T A в L E 5. Differences in weekly care costs $(f)$ between people living alone and with carers at all time points

\begin{tabular}{|c|c|c|c|c|c|c|c|}
\hline \multirow[b]{2}{*}{ Cost item } & \multicolumn{2}{|c|}{$\begin{array}{l}\text { Co-resident carer } \\
\quad \mathrm{N}=64\end{array}$} & \multicolumn{2}{|c|}{$\begin{array}{l}\text { Alone } \\
\mathrm{N}=37\end{array}$} & \multicolumn{3}{|c|}{$\begin{array}{l}\text { Probability of difference } \\
\left.\text { (t-test } \log _{10}\right) ; \text { Mann-Whitney }\end{array}$} \\
\hline & Mean TI & Median $T_{I}$ & Mean $T_{I}$ & Median $T_{I}$ & Time I & Time 2 & Time $3^{3}$ \\
\hline Accommodation (pwd) & I76.74 & I66.80 & 2II.I3 & 221.20 & 0.003; 0.00I & Ns & Ns \\
\hline Medication & I 2.77 & $3 \cdot 40$ & $4 \cdot 5^{\mathrm{O}}$ & 0.07 & 0.010; 0.002 & 0.04I； 0.I39 & Ns \\
\hline Inpatient & $3^{6.12}$ & 0.00 & 8.63 & 0.00 & $\mathrm{Ns}$ & $\mathrm{Ns}$ & Ns \\
\hline Outpatient & 4.63 & 0.00 & 2.23 & 0.00 & $0.025 ; 0.026$ & Ns & $0.002 ; \mathrm{Ns}$ \\
\hline Day hospital & I. 40 & 0.00 & 0.22 & 0.00 & $\mathrm{Ns}$ & Ns & $\mathrm{Ns}$ \\
\hline Day care & 80.07 & 0.00 & $85 \cdot 43$ & 0.00 & Ns & Ns & 0.007 ; Ns \\
\hline Community health & 9.25 & 3.85 & $9 \cdot 3^{2}$ & 0.00 & 0.05I ; 0.0I6 & Ns & $\mathrm{Ns}$ \\
\hline PCG & 7.29 & $3 \cdot 45$ & $3.2 \mathrm{I}$ & 0.00 & 0.0OI $;<0.001$ & Ns & Ns \\
\hline Social services & $97 \cdot 35$ & 43.82 & I20.19 & $30.7 \mathrm{I}$ & $\mathrm{Ns}$ & Ns & Ns \\
\hline Other & 0.09 & 0.00 & 0.12 & 0.00 & Ns & $\mathrm{Ns}$ & $\mathrm{Ns}$ \\
\hline Respite & I 4.55 & 0.00 & I I. 76 & 0.00 & Ns & $<0.001 ; 0.02 \mathrm{I}$ & $<$ o.0OI; Ns \\
\hline NHS total & 63.01 & 21.37 & $23 \cdot 3^{8}$ & 2.78 & $0.000 ; 0.001$ & $\mathrm{Ns}$ & $\mathrm{Ns}$ \\
\hline All services & I6o. 44 & I 23.60 & I 45.17 & 83.87 & $\mathrm{Ns}$ & Ns & Ns \\
\hline Informal care & 249.07 & І 23.56 & II9.94 & 42.00 & $0.093 ; 0.03 \mathrm{I}$ & na & Ns \\
\hline
\end{tabular}

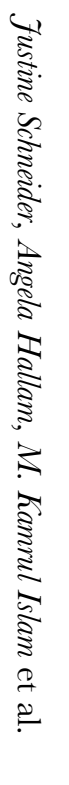

Note: pwd - person with dementia. 
$5^{6}$ survivors at Time 3 who had GDS of $4+$ at Time I. For the more severely affected sub-sample, total costs including accommodation were also higher for community-residents than for people in non-domestic care (independent means $\mathrm{t}=3.45, \mathrm{p}=$ o.00I, 95 per cent Confidence Interval £277 to $f 73)$. On the whole, the differences in costs noted for the whole sample apply equally to those more severely affected people.

\section{Changes for individuals over time}

Between Time I and Time 2 a high proportion of people with dementia moved into non-domestic care and some died, leaving only 64 of the original sample of Ior living in the community after on average seven months since the first interview. Between Time I and Time 2, the costs of accommodation for all people with dementia increased significantly, from a mean of $\AA_{203}$ overall (standard deviation 84) to $£ 265$ overall (standard deviation IIo). An increase in inpatient care was marginally significant (paired $\mathrm{t}=\mathrm{I} .93, \mathrm{p}=\mathrm{0.0 \textrm {I } 6}$; Wilcoxon $\mathrm{Z}=\mathrm{I.92}, \mathrm{p}=0.054$ ), and could reflect growing levels of disablement or dementia in the sample population. Perhaps for the same reason, day centre use declined for these 'survivors' between Time I and Time 2, as did the costs of primary care. Since this analysis included people in all three types of living situations, a shift towards non-domestic care (as illustrated in Figure I) can also account for the decline in the services noted here. As already demonstrated, people in non-domestic settings use fewer services than people in community settings (Tables 2-4).

Between Time I and Time 3 the cost of accommodation for the person with dementia rose on average, while the accommodation cost for the carer and the person with dementia taken together declined, probably reflecting the higher proportion of people living in non-domestic settings at Time 3 . The decline in day centre use remained significant at Time 3 despite sample attrition, and a new discrepancy appeared; a significant drop in the costs of informal care between Time I and Time 3. Given these changes, and the shift in living arrangements, it is remarkable that the total costs of informal care, formal services and accommodation differ very little between Time I (mean $£ 5$ oo per week) and Time 3 (mean $£ 55^{\mathrm{I}} 3$ per week). With the total costs remaining fairly stable, the change in proportions of funding may be taken as evidence of substitution.

For greater clarity, we looked at those people who remained throughout the study period living in the community $(n=40)$. The numbers were not large enough to disaggregate those living alone and those with co-resident carers. They constituted a small sub-group of the original sample, yet the pattern of change in their costs reveals a clear increase in social services 
T а в L е 6. Weekly care costs $(f)$ of community dwellers: Time I and Time 3

\begin{tabular}{|c|c|c|c|c|c|c|c|}
\hline Cost item & $\begin{array}{c}\text { Mean } \\
\text { TI }\end{array}$ & $\begin{array}{l}\text { Standard } \\
\text { deviation }\end{array}$ & $\begin{array}{c}\text { Mean } \\
\mathrm{T}_{3}\end{array}$ & $\begin{array}{l}\text { Standard } \\
\text { deviation }\end{array}$ & $\mathrm{N}$ & $\begin{array}{c}\text { Paired } \\
\text { t-tests } \\
\text { p }\end{array}$ & $\begin{array}{c}\text { Wilcoxon } \\
\text { paired ranks } \\
\text { p }\end{array}$ \\
\hline Accommodation (pwd) & I84.22 & $39 \cdot 79$ & 177.17 & $3^{8.48}$ & 39 & 0.240 & $0.3 \mathrm{I} 3$ \\
\hline Medication & $\mathrm{I} 3.24$ & 28.12 & 13.70 & 29.23 & 40 & 0.575 & 0.623 \\
\hline Outpatient care & 3.69 & 6.40 & $2.6 \mathrm{I}$ & 8.68 & 39 & 0.220 & 0.070 \\
\hline Inpatient & 49.07 & $\mathrm{I} 43.72$ & 33.89 & 86.30 & 40 & o.69I & 0.248 \\
\hline Day hospital & 0.20 & I. 29 & 0.00 & 0.00 & 39 & 0.324 & $0.3 \mathrm{I} 7$ \\
\hline Day centre & $69 \cdot 5^{8}$ & 99.87 & 62.00 & $\mathrm{IO} 3 \cdot 42$ & 39 & 0.944 & 0.396 \\
\hline Community health & II.33 & I7.9I & II. 84 & I8.44 & 40 & 0.940 & 0.923 \\
\hline Primary care & 8.19 & I3.68 & $7 \cdot 48$ & II. 57 & 40 & 0.897 & 0.827 \\
\hline Social services & 80.85 & 103.77 & II 9.2 I & I $26.3^{8}$ & 40 & $0.02 \mathrm{I}$ & 0.003 \\
\hline Other & o.I9 & 0.94 & $3 \cdot 43$ & $2 \mathrm{I} \cdot 4^{2}$ & 39 & 0.479 & 0.655 \\
\hline Respite & II. 32 & $45 \cdot 39$ & I7.25 & $3^{8.98}$ & 39 & 0.045 & 0.278 \\
\hline All NHS costs & $79 \cdot 3^{8}$ & I63.92 & $55 \cdot 76$ & 9I.04 & 40 & 0.125 & 0.005 \\
\hline Total service costs & I 60.42 & I94.57 & I78.3I & I $44 \cdot 44$ & 40 & 0.359 & O.IOI \\
\hline Informal care & I77.I 6 & $219 \cdot 4^{6}$ & I 68.42 & I83.8I & 40 & $0.6 \mathrm{IO}$ & 0.772 \\
\hline All costs & 523.25 & 324.89 & $5^{21.10}$ & $259 \cdot 18$ & $3^{8}$ & 0.887 & 0.777 \\
\hline
\end{tabular}

Note: pwd-person with dementia.

costs, and a decline in costs borne by the NHS (Table 6). No other category of costs differences attains significance on both tests used.

\section{Influence of disability on costs}

Bivariate correlations between a range of disability and costs variables were tested for significance. These showed that some of the Clinical Dementia Rating Scale sub-scales were positively associated with costs. For instance, the memory subscale was correlated with community health care costs $(\mathrm{r}=0.25 ; \mathrm{p}=0.007)$, as was the orientation sub-scale $(\mathrm{r}=0.23 ; \mathrm{p}=0.0 \mathrm{I}) . \mathrm{We}$ found the personal care subscale to be positively associated with the costs of respite care $(\mathrm{r}=0.20 ; \mathrm{p}=0.029)$. These associations all have face validity, since community health care and respite care would be targeted at the patients with greater problems of memory and orientation. Total NHS costs were associated with respite costs $(\mathrm{r}=0.24 ; \mathrm{p}=0.006)$, which suggests that both are dependent on severity of disability. The costs of specific informal care tasks were positively correlated with day care $(\mathrm{r}=0.22 ; \mathrm{p}=$ 0.o $\mathrm{oo})$, social services inputs $(\mathrm{r}=0.23 ; \mathrm{p}=0.009)$ and consequently with all service costs $(r=0.17 ; p=0.048)$. Supervision costs correlated with the same variables, and somewhat more highly in each case $(\mathrm{p}<$ o.oor $)$.

The complex associations noted here indicated a need for multivariate analysis to investigate more fully the variables associated with costs. It was clear from these analyses that the predictors of formal and informal costs 
must include measures of disability, together with the variables describing living arrangements that yielded so many significant differences presented in the tables. First, all formal service costs at Time I were taken as the dependent variable, using multiple linear regression analysis to find the most suitable model. The model was tested for Time 3. The two analyses were repeated with informal care costs as the dependent variable, again, testing the resulting model on Time 3 data. We found that five variables could explain significant amounts of the variance in formal service costs and in informal service costs. The resulting models are shown in Table 7. The 'fit' is better for informal care at Time $\mathrm{I}$ and for formal care at Time 3. In both cases, the equation explains about 30 per cent of the variation in costs. Controlling for the other variables shown, including disability, nondomestic care appears to have a negative influence on costs of both formal and informal care. Cognitive disability, as measured by the GDS, appears to increase costs, but this variable is only significant in relation to informal care at Time I. Impairment in terms of ADL is significant in both of the more powerful equations. Curiously, it is associated with lower informal inputs at Time I, and higher formal inputs at Time 3. Informal care and formal care are significantly positively associated with each other (this tends to support 'supplementation' more than 'substitution'). Controlling for all of these variables, co-residence does still have a positive impact on informal costs at Time I.

\section{Discussion}

The main messages from this study highlight the high costs of informal care, and the fact that these are not offset by formal care, but that the two are positively associated. Contrary to popular belief, admission to residential care proved less costly than community care when informal inputs were taken into account.

\section{The contribution of informal carers}

This study shows that, even using a very conservative estimate of its costs, informal care is a considerable element in the total costs of care (Table I). Indeed, at both Time I and Time 3, the inputs from co-resident informal carers exceeded those from formal services. This highlights the importance of taking informal inputs into account in any analysis of costs of care. Our findings are in keeping with other studies of informal care inputs for people with dementia living in the community, reviewed by McDaid (200I). These 
T А В L E 7. Results of regression analyses on formal and informal care costs

\begin{tabular}{|c|c|c|c|c|c|c|}
\hline \multirow[b]{2}{*}{$\begin{array}{l}\text { Dependent variable: } \\
\text { All formal service costs }\end{array}$} & \multicolumn{3}{|c|}{ Time I equation } & \multicolumn{3}{|c|}{ Time 3 equation } \\
\hline & $\begin{array}{l}\text { Standardized } \\
\text { coefficients }\end{array}$ & $\mathrm{t}$ & Sig. & $\begin{array}{l}\text { Standardized } \\
\text { coefficients }\end{array}$ & $\mathrm{t}$ & Sig. \\
\hline & Beta & & & Beta & & \\
\hline (Constant) & & I.II9 & 0.265 & & 0.373 & $0.7 \mathrm{II}$ \\
\hline Non-domestic care & -0.330 & -2.717 & 0.008 & -0.589 & -2.704 & 0.009 \\
\hline Global deterioration scale & 0.096 & $0.93^{8}$ & $0.35^{\circ}$ & 0.065 & $0.55^{8}$ & 0.579 \\
\hline ADL & 0.043 & 0.476 & 0.635 & 0.301 & 2.607 & 0.012 \\
\hline Informal care costs & $0.2 \mathrm{I} 5$ & 2.037 & 0.044 & $0 . \mathrm{I} 3 \mathrm{I}$ & I.04I & 0.302 \\
\hline \multirow[t]{3}{*}{ Co-resident } & -0.078 & -0.700 & 0.485 & $-\mathrm{O}$ II 4 & -0.544 & $0.5^{89}$ \\
\hline & \multicolumn{3}{|c|}{$\mathrm{R}^{2}$ o.I7 (Adj. 0.I3), F $4.25(5$, IO7) $\mathrm{p}=0.00 \mathrm{I}$} & \multicolumn{3}{|c|}{$\mathrm{R}^{2}$ o.35 (Adj. o.29), F $5.68(5,53) \mathrm{p}<$ o.0oI } \\
\hline & \multicolumn{3}{|c|}{ Time I equation } & \multicolumn{3}{|c|}{ Time 3 equation } \\
\hline \multirow[t]{2}{*}{$\begin{array}{l}\text { Dependent variable: } \\
\text { Informal care costs }\end{array}$} & $\begin{array}{l}\text { Standardized } \\
\text { coefficients }\end{array}$ & $\mathrm{t}$ & Sig. & $\begin{array}{l}\text { Standardized } \\
\text { coefficients }\end{array}$ & $\mathrm{t}$ & Sig. \\
\hline & Beta & & & Beta & & \\
\hline (Constant) & & 0.394 & 0.694 & & -0.486 & 0.629 \\
\hline Non-domestic care & $-0.28 \mathrm{I}$ & -2.564 & 0.012 & -0.246 & -0.988 & 0.327 \\
\hline Global deterioration scale & $0.3^{2 \mathrm{I}}$ & 3.694 & 0.000 & O.I55 & I. 253 & 0.216 \\
\hline $\mathrm{ADL}$ & -0.198 & -2.487 & 0.0I4 & 0.097 & 0.737 & 0.464 \\
\hline Health and social care costs & 0.I74 & 2.037 & 0.044 & O.I53 & I.04I & 0.302 \\
\hline \multirow[t]{2}{*}{ Co-resident } & 0.165 & I. 663 & 0.099 & 0.148 & 0.653 & $0.5^{17}$ \\
\hline & \multicolumn{3}{|c|}{$\mathrm{R}^{2}$ 0.32 (Adj. 0.29), F г0.33 (5, I07) $\mathrm{p}<$ о.00I } & \multicolumn{3}{|c|}{$\mathrm{R}^{2}$ o.24 (Adj. o.I7), F $3.37(5,53) \mathrm{p}<$ o.oI } \\
\hline
\end{tabular}


estimate informal care as a proportion of total costs of care to range between $3^{6}$ per cent and 85 per cent depending upon the elements included in the total. Accommodation is a key variable.

By comparison, the 'Resource implications study' of the Medical Research Council 'Cognitive Function and Ageing' study, which contains a more representative sample of frail elderly people, reports separately on informal care, rather than integrating its costs with other service costs (McNamee et al. I999, 200 ; Bamford et al. I998). Moreover, the latter study measures the financial costs to carers, but not the costs of carers' time or labour. In line with other studies (reviewed by McDaid 200I) our findings confirm that costs estimates that omit full informal care costs will be underestimated by a considerable amount. The research reported here indicates that the amount by which costs may be underestimated varies according to living arrangements. For people living alone there could be an underestimate of 25 per cent, but for co-resident carers costs estimates may be 40 per cent too low.

\section{Predictors of costs}

An equation devised for Time I formal costs data was robust enough to explain Time 3 costs data, though with reduced power. Informal care had a marginally positive association with formal care, which confirms the supplementation hypothesis. The strongest (negative) predictor of formal care costs was living in residential care, but this is overstated because we did not disaggregate the care element from residential care costs. A similar set of variables could be used, with similar results, to explain up to one-third of the variation in informal care costs. The factor that was most significantly associated with informal inputs was level of dementia, but physical disability and living in residential care were associated with receipt of less informal care. It is interesting to note that performance in ADL was negatively associated with informal care at Time I. By contrast, at Time 3, it was positively associated with formal inputs. The latter finding may be explained by disability level qualifying people with dementia for some services. Further investigation would be needed to explain why it appears that less informal care was supplied to people with lower ADL scores.

\section{Is non-domestic (residential) care less costly?}

Non-domestic care is commonly perceived as the more costly care option, when only financial costs to the patient and family are taken into account. Here, we demonstrate that, contrary to expectations, the costs of domestic 
care including informal inputs, are higher than the costs of non-domestic care. This holds true even when level of dementia is taken into account. Taking co-residence, dependency and other care inputs into account, being in non-domestic care has a powerful, negative impact on costs of both formal and informal care.

Considering the total costs to society, it therefore appears that nondomestic care might be a cost-effective option for some people with moderate to severe dementia. To prove this hypothesis we would need to incorporate quality of life or mortality outcomes into the analysis. We would also need to ensure that local non-domestic care costs reflect the true opportunity costs of looking after individuals with dementia in these settings. This could vary because of local residential care pricing policy or hidden subsidies, or even because of peculiarities of the local housing market. Costs might also be misleading due to cross-subsidisation between different residents in a given home, whereby the higher care costs of people with dementia are masked by lower costs of people who do not have dementia. Most importantly, the analysis would need to be performed on a sample whose representativeness was higher than the one studied here.

When it is asserted that community care costs more to society at large than non-domestic care, it is important to specify where the costs fall. The cost burden to different groups differs greatly between settings. The impact of admission to non-domestic care falls largely on social services, subject to means-testing of the client. Using the figures from Table I, leaving aside for the sake of argument the contributions made by families to residential care charges, and assuming that social services are responsible for all the costs of non-domestic accommodation and that families are responsible for domestic accommodation as well as informal care, Figure 2 presents the distribution of the cost burden. While 86 per cent of a non-domestic placement would fall to social services, I7 per cent of costs for a person with a co-resident carer and 26 per cent of those for a person living alone would fall to social services. For a family whose financial assets would entitle them to financial support, the impact on social services of a preventable admission to care could amount to trebling the costs of meeting the needs of that family.

\section{Supplementation or substitution?}

The regression equations at Time i indicate that supplementation occurred in the early stages of the study, because formal service input was a positive, marginally significant predictor of informal care costs $(p=0.044)$. However, the change in the proportions of care provided between Time I and Time 3 reflect a shift towards non-domestic care, and a corresponding reduction in 


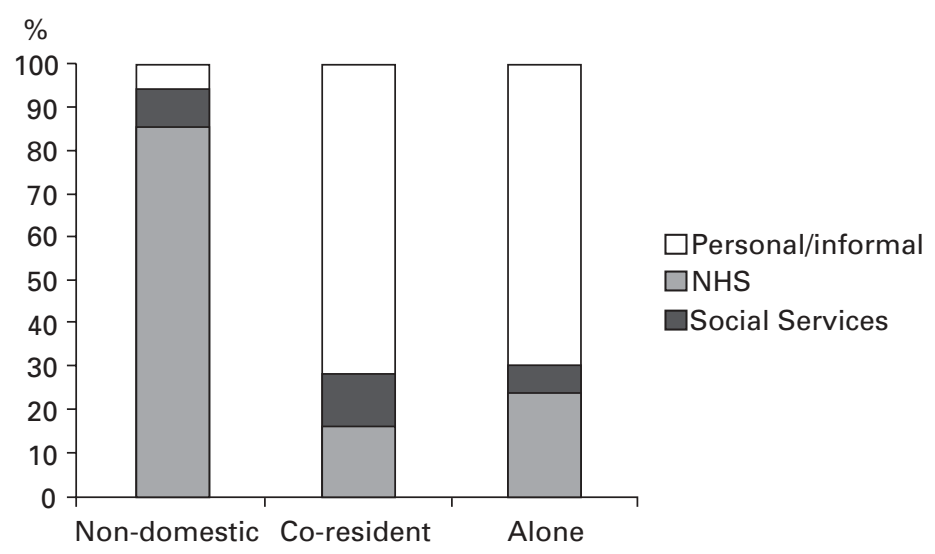

Figure 2. Costs distribution by living arrangement (Time I).

informal care, while formal services stayed about the same. This could be interpreted as substitution of non-domestic care for informal care, and indeed also for formal care (because the increase might otherwise have been greater). The picture that emerges is therefore one of supplementation in the early part of the caring 'career', followed by substitution in the later part. Again, a more representative sample would be required to test this hypothesis.

\section{Implications}

The data presented in this paper attempt to make explicit all the costs of caring for people with dementia in the community. While the sample is relatively small and selected from medical caseloads, much of the information reported here could be used to explore similar, local data-sets. As illustrated in our discussion of the costs burden, it can be used to appraise options for configuring services, for instance to estimate the marginal costs of interventions targeted at carers. The dataset could also be used to augment the information that can be inferred from larger, more representative studies that have not measured informal care costs. Combined with reliable estimates of the prevalence of dementia, these costs could also be used to estimate the global costs of the illness.

In this study, we have identified several key factors that are associated with both formal and informal costs of care, and which may be used to help promote equity in planning, in service development and in resource allocation. Altogether, the dataset can be expected to prove useful in making explicit the role of informal carers in relation to other services, as well as 
indicating ways to improve the situation of growing numbers of carers for people with dementia and the people for whom they care.

\section{NOTES}

I Statistical comparisons were made using analysis of variance to compare multiple means. Where two groups were compared, t-tests (independent or paired, as appropriate) were applied to continuous data. Where it might be argued that the data were non-parametric, such as the GDS and ADL scales, and where the distribution of the costs was highly skewed, Mann-Whitney U tests for independent means or Wilcoxon tests for paired means were applied as well, to confirm or disconfirm any significant results.

2 All prices were annuitised over a 6o-year period at an eight per cent discount rate. The weekly cost for local authority property includes management and maintenance costs based on the expenditure per dwelling per annum given in Housing Revenue Account Statistics 1998 (Chartered Institute of Public Finance Accountants I999).

3 Drugs were grouped by their treatment of systems or areas of the body (such as cardiovascular or respiratory problems, or musculoskeletal and joint diseases) in line with British National Formulary specifications (BNF; British Medical Association and Royal Pharmaceutical Society of Great Britain 1998). Costs were taken from the BNF and applied according to the dosage received by subjects.

4 When applying parametric tests which assume a normal distribution, we give greater credence to the results for variables that are in fact normally distributed and used by most of the sample. Additionally, we confirm our results using non-parametric tests of independent means (Mann-Whitney) or paired means (Wilcoxon) as appropriate.

5 The $t$ tests of independent means showed that people in non-domestic care had significantly higher GDS scores than people with co-resident carers (mean 5.IO, standard deviation I.I4, as compared to 4.42 , standard deviation I.36, $\mathrm{p}=0.02 \mathrm{I}$; Mann-Whitney $\mathrm{p}=0.03^{2}$ ). Similarly, people with co-resident carers scored higher than people living alone (mean 3.72, standard deviation I.I4, $\mathrm{p}=0.015 ; \mathrm{M}-\mathrm{W}$ $\mathrm{p}=0.009$ ).

\section{Disclaimer}

This work was undertaken by the authors at the Institute of Psychiatry, King's College, London with funding from the Department of Health. The views expressed in the publication are those of the authors and not necessarily those of the Department of Health.

\section{References}

Bamford, C., Gregson, B., Farrow, G., Buck, D., Dowswell, T., McNamee, P. and Bond, J. 1998. Mental and physical frailty in older people: the costs and benefits of informal care, Resource Implications Study of Medical Research Council Cognitive Functioning and Ageing Study. Ageing and Society, I 8, 317-54.

Bass, D. M., Noelker, L. S. and Rechlin, L. R. I996. The moderating influence of service use on negative caregiving consequences. Fournals of Gerontology Series B-Psychological Sciences and Social Sciences, 5I, Si2I-3I. 
Beecham, J. and Knapp, M. R. J. I992. Costing psychiatric interventions. In Thornicroft, G. J., Brewin, C. R. and Wing, J. K. (eds), Measuring Mental Health Needs. Gaskell, London, I79-90.

British Medical Association and Royal Pharmaceutical Society of Great Britain I998. British National Formulary, Number 35 (March 1998). British Medical Association and Royal Pharmaceutical Society of Great Britain, London.

Chisholm, D. 2000. 'Mind how you go': issues in the analysis of cost-effectiveness in mental health care. PSSRU and CEMH Mental Health Research Review, 7, 33-8.

Chartered Institute of Public Financial Accountants 1999. Housing Revenue Account Statistics I998. CIPFA Statistical Information Service, London.

Davis, K., Marin, D., Kane, R., Patrick, D., Peskind, E., Raskind, M. and Puder, K. I997. The Caregiver Activity Survey (CAS): development and validation of a new measure for caregivers of persons with Alzheimer's disease. International fournal of Geriatric Psychiatry, I 2, 978-88.

Department of Health 2000. The NHS Plan: The Government's Response to the Commission on LongTerm Care. Cm 48ı8-II. Her Majesty's Stationery Office, London.

Department of Environment Transport and Roads (DETR) 1998. Housing and Construction Statistics 1987-1997. DETR, London.

Drummond, M. F. and Jefferson, T. O. I996. Guidelines for authors and peer reviewers of economic submissions to the BMJ. British Medical Fournal, 31 3, 275-83.

Edelman, P. and Hughes, S. I990. The impact of community care on provision of informal care to homebound elderly persons. Fournal of Gerontology, 45, 874-84.

Government Statistical Service 1998. Housing and Construction Statistics, Great Britain, June Quarter 1998, Part 2. Stationery Office, London.

Gray, A., Marshall, M., Lockwood, A. and Morris, J. 1997. Problems in constructing economic evaluations alongside clinical trials. British Fournal of Psychiatry, I 7o, 47-52.

Greene, V. 1983. Substitution between formally and informally provided care for the impaired elderly in the community. Medical Care, 21, 609-19.

Halifax Building Society I998. Halifax House Price Index, Fourth Quarter, I998. Halifax plc, Halifax, Yorkshire.

Hughes, G. P., Berg, L., Danziger, W. L., Coben, L. A. and Martin, R. L. I982. A new clinical scale for the staging of dementia. British Fournal of Psychiatry, $\mathbf{1 4 0}$, 566-72.

Islam, M. K. I999. Costing informal care: methods and practice: the case of the south London costs of dementia study. MSc dissertation, Department of Economics and Related Studies, University of York, York.

Katz, S., Ford, A. B., Moskowitz, R. W., Jackson, B. A. and Jaffe, M. W. I963. Studies of illness in the aged. The index of ADL: a standardised measure of biological and psychosocial function. Fournal of the American Medical Association, 185, 914-19.

Knapp, M. and Beecham, J. I995. Reduced-list costings : examination of an informed short cut in mental health research. Health Economics, 2, 313-22.

Levin, E., Moriarty, J. and Gorbach, P. I994. Better for the Break. Her Majesty's Stationery Office, London.

Lyons, K. and Zarit, S. I999. Formal and informal support: the great divide. International Journal of Geriatric Psychiatry, 14, I83-96.

Marin, D., Dugue, M., Schmeidler, J., Santoro, J., Neugroschl, J., Zaklad, G., Brickman, A., Schnur, E., Hoblyn, J. and Davis, K. 2000. The Caregiver Activity Survey (CAS): Longitudinal validation of an instrument that measures time spent care-giving for individuals with Alzheimer's disease. International Fournal of Geriatric Psychiatry, I5, $680-6$.

McDaid, D. 200I. Estimating the costs of informal care for people with Alzheimer's disease: methodological and practical challenges. International fournal of Geriatric Psychiatry, I6, $4{ }^{\mathrm{OO}}-5$. 
McNamee, P., Gregson, B., Buck, D., Bamford, C., Bond, J., Wright, K. I999. Costs of formal care for frail older people in England: the resource implications study of the MRC cognitive function and ageing study. Social Science and Medicine, 48, 33 I-4I.

McNamee, P., Bond, J. and Buck, D. 200r. Costs of dementia in England and Wales in the 2Ist century. British Fournal of Psychiatry, I 79, 26I-6.

Mittelman, M. S., Steinberg, G., Shulman, E., Mackell, J., Ambinder, A. and Cohen, J. I993. An intervention that delays institutionalisation of Alzheimer's disease patients treatment of spouse-care-givers. Gerontologist, 33, 730-40.

Netten, A., Dennett, J. and Knight, J. 1998. Unit Costs of Health and Social Care 1998. PSSRU, University of Kent at Canterbury, Canterbury, Kent.

O'Rouke, N. and Tuokko, H. 200o. The psychological and physical costs of care giving: the Canadian study of health and aging. Fournal of Applied Gerontology, 19, 389-404.

Office of National Statistics i999a. New Earnings Survey 1998. Office of National Statistics, Newport, Wales.

Office of National Statistics i999b. Family Spending 1997-98. Office of National Statistics, London.

Reisberg, B., Ferris, S. H., de Lean, M. J. and Crook, T. I982. The Global Deterioration Scale (GDS) for assessment of primary degenerative dementia. American Fournal of Psychiatry, I39, г136-9.

Royal Commission on Long Term Care 1999. With Respect to Old Age: Executive Summary. Department of Health, London.

Schneider, J., Hallam, A., Murray, J., Foley, B., Atkins, L., Banerjee, S., Islam, K. and Mann, A. 2002. Formal and informal care for people with dementia: factors associated with service receipt. Aging and Mental Health, 6, 255-65.

Thompson, C. and Spilsbury, K. I998. Support for carers of people with Alzheimer's type dementia (Cochrane Review). In The Cochrane Library, Issue I, 2002. Update Software, Oxford.

Address for correspondence:

Accepted 20 November 2002

Justine Schneider, Centre for Applied Social Studies, University of Durham, Old Shire Hall, Durham DHi ${ }_{3} \mathrm{HP}$, UK.

e-mail: Justine.Schneider@durham.ac.uk 